\title{
Human mesenchymal stem cells enhance cancer cell proliferation via IL-6 secretion and activation of ERK1/2
}

\author{
AGMAL SCHERZAD, MAGDALENA STEBER, THOMAS GEHRKE, KRISTEN RAK, KATRIN FROELICH, \\ PHILIPP SCHENDZIELORZ, RUDOLF HAGEN, NORBERT KLEINSASSER and STEPHAN HACKENBERG
}

\author{
Department of Oto-Rhino-Laryngology Plastic, Aesthetic and Reconstructive, Head and Neck Surgery, \\ Julius-Maximilian-University Wuerzburg, D-97080 Wuerzburg, Germany
}

Received March 1, 2015; Accepted April 20, 2015

DOI: 10.3892/ijo.2015.3009

\begin{abstract}
Human mesenchymal stem cells (hMSC) are frequently used in tissue engineering. Due to their strong tumor tropism, hMSC seem to be a promising vehicle for anticancer drugs. However, interactions between hMSC and cancer are ambiguous. Particularly the cytokines and growth factors seem to play an important role in cancer progression and metastasis. The present study evaluated the effects of hMSC on head and neck squamous cell carcinoma (HNSCC) cell lines (FaDu and HLaC78) in vitro. hMSC released several cytokines and growth factors. $\mathrm{FaDu}$ and $\mathrm{HLaC} 78$ showed a significant enhancement of cell proliferation after cultivation with hMSC-conditioned medium as compared to control. This proliferation improvement was inhibited by the addition of anti-IL-6. The western blot showed an activation of Erk1/2 in FaDu and HLaC78 by hMSC-conditioned medium. HNSCC cell lines expressed EGFR. The current study confirms the importance of cytokines secreted by hMSC in cancer biology. Especially IL-6 seems to play a key role in cancer progression. Thus, the use of hMSC as a carrier for cancer therapy must be discussed critically. Future studies should evaluate the possibility of generating genetically engineered hMSC with, for example, the absence of IL-6 secretion.
\end{abstract}

\section{Introduction}

Human mesenchymal stem cells (hMSC) are undifferentiated cells capable of self-renewal and proliferation (1). Under certain conditions hMSC are able to differentiate into diverse mesenchymal cell types, e.g., osteocytes, adipocytes and

Correspondence to: Dr Agmal Scherzad, Department of Oto-RhinoLaryngology, Plastic, Aesthetic and Reconstructive, Head and Neck Surgery, Julius-Maximilian-University Wuerzburg, Josef-SchneiderStr. 11, D-97080 Wuerzburg, Germany

E-mail: scherzad_a@ukw.de

Key words: MAPK (ERK 1/2), HNSCC, human mesenchymal stem cells, IL-6, cytokines chondrocytes (2). Due to their ability to migrate as well as the capability to differentiate, hMSC play an important role in the preservation and re-creation of tissue integrity. Inflammation and tissue damage are strong chemoattractants for hMSC, similar to the recruitment of leucocytes into inflamed tissue sites (3-5). Tissue-specific homing of leukocytes depends on cytokines, tissue-specific adhesion molecules, and homing receptors (6). Von Lüttichau and colleagues demonstrated functional expression of several chemokine receptors on primary isolated hMSC (7).

Cancer tissue exhibits similar cytokine patterns as inflamed tissue (8). Hence, there is a strong tropism of hMSC towards tumors (9). Furthermore, hMSC integrate into the tumor directly and build parts of the cancer microenvironment $(9,10)$. Thus, several studies have suggested that hMSC would be an appropriate biological carrier, for example, for drug delivery therapy $(11,12)$.

However, interactions between hMSC and cancer are ambiguous. Some studies show tumor progression and enhancement of the tumor metastatic potential by hMSC. This progression is induced by cell-cell contact as well as by the secretion of several cytokines and growth factors by hMSC such as interleukin-6 (IL-6), epidermal growth factor (EGF), vascular epidermal growth factor (VEGF), insulin-like growth factor (IGF)-1 or transforming growth factor (TGF)- $\beta$ in a paracrine manner (13-18). Some of these, especially EGF and IL-6, may play an important role in tumor progression and metastasis. The activation of mitogen-activated protein kinase (MAPK) pathways was shown to play an important role in cytokine-induced tumor progression $(19,20)$. MAPK pathways link extracellular signals to the machinery that controls fundamental cellular processes (21). Especially the extracellular signal-regulated kinase (ERK) $1 / 2$ is activated by growth factors, which in turn is responsible for cell proliferation, differentiation, apoptosis and migration (21).

In a previous study, we were able to show an increase in tumor proliferation as well as motility in the presence of hMSC. Cancer cell lines showed resistance towards paclitaxel after co-cultivation with hMSC $(18,22)$. The aim of the present study was to evaluate whether hMSC induce an activation of the MAPK pathway in vitro. Furthermore, the effect of IL-6 on cell proliferation was also investigated. 


\section{Materials and methods}

hMSC isolation and culture. The cells were harvested and prepared from 5 voluntary patients with written informed consent from the Department of Orthopedics, Koenig-LudwigHaus. The study was approved by the Ethics Committee of the Medical Faculty of the University of Wuerzburg (12/06). Bone marrow was collected under aseptic conditions and cells were isolated according to the protocol described by Lee et al (23). Ficoll density-gradient centrifugation was used in order to isolate hMSC (30 $\mathrm{min}, 1,300 \mathrm{rpm}$, density $=1,077 \mathrm{~g} / \mathrm{ml}$, Biochrom AG, Berlin, Germany). After collection of the cells from the interphase, a washing step with phosphate buffered saline (PBS) (Roche Diagnostics GmbH, Mannheim, Germany) containing 2\% FCS followed. After centrifugation the cell pellet was resuspended in expansion medium (DMEM-EM), which was made of Dulbecco's modified Eagle's medium (DMEM) (Gibco Invitrogen, Karlsruhe, Germany) containing 10\% FCS (Linaris, Wertheim-Bettingen, Germany), $1 \%$ penicillin and streptomycin (Sigma-Aldrich, Schnelldorf, Germany). Cells were incubated for $24 \mathrm{~h}$ at $37^{\circ} \mathrm{C}$ and $5 \% \mathrm{CO}_{2}$. The medium was changed every other day. The morphology of hMSC was analyzed by inverted microscopy (Leica DMI 4000B Inverted Microscope, Leica Microsystems, Wetzlar, Germany).

Multidifferentiation capacity. Osteogenic differentiation was carried out in a 24-well plate (BD Falcon, Heidelberg, Germany) with $1 \times 10^{4}$ cells/well until $70 \%$ confluence was reached. The expansion medium DMEM-EM additionally contained $10^{-7} \mathrm{M}$ dexamethasone, $10^{-3} \mathrm{M} \beta$-glycerophosphate and $2^{-4} \mathrm{M}$ ascorbate-2-phosphate (all Sigma-Aldrich). The von Kossa method was used to show the presence of calcium mineral components. Adipogenic differentiation medium was made of DMEM-EM containing $10^{-7} \mathrm{M}$ dexamethasone and $10^{-9} \mathrm{~g} / \mathrm{ml}$ recombinant human insulin (both Sigma-Aldrich). Staining with Oil Red O confirmed the presence of intracellular lipid droplets.

For chondrogenic differentiation the pellet culture system was used. The cell pellets were cultured in a defined chondrogenic differentiation medium (Lonza, Basel, Switzerland) supplemented with $10^{-9} \mathrm{~g} / \mathrm{ml}$ transforming growth factor- $\beta 3$ (Sigma-Aldrich). Cells were cultivated for 3 weeks. Thereafter, the pellets were embedded in Optimal Cutting Temperature Paraffin (Tissue-Tek ${ }^{\circledR}$ O.C.T ${ }^{\mathrm{TM}}$; Sakura Finetek, Zoeterwoude, The Netherlands). Cryosections were stained with Alcian blue to show the presence of glycosamineglycane.

Expression of cell surface markers. Flow cytometry was used in order to confirm surface antigen markers. hMSC $\left(1 \times 10^{6}\right)$ were incubated with anti-CD105, anti-CD90, anti-CD44 and anti-CD34 (all antibodies were purchased from BD Bioscience, Heidelberg, Germany). Cell surface analyses were performed by flow cytometry (FACSCanto ${ }^{\mathrm{TM}}$; BD Bioscience).

HNSCC cell line FaDu and HLaC78. The head and neck squamous carcinoma cell lines $\mathrm{FaDu}$ and $\mathrm{HLaC} 78$ were used $(24,25)$. Cells were grown in DMEM-EM and cultured at $37^{\circ} \mathrm{C}$ with $5 \% \mathrm{CO}_{2}$ in culture flasks. Every other day the medium was replaced. After reaching $70-80 \%$ confluence cells were trypsinized with $0.25 \%$ trypsin (Gibco Invitrogen), washed with PBS and seeded in new flasks or treatment wells. Experiments were performed using cells in the exponential growth phase. FaDu and HLaC78 were incubated with the supernatants of hMSC (hMSC-sup). The following experiments were carried out in order to evaluate the effects of cytokines released by hMSC on FaDu and HLaC78.

Cytokine analysis of hMSC-sup with the dot blot assay. The dot blot assay (RayBiotech Inc., Norcross, GA, USA) was used as a semi-quantitative method for determining hMSC cytokine secretion. After an incubation period of $48 \mathrm{~h}$ in DMEM without supplements, the supernatants were collected and investigated for the presence of cytokines. The assay was performed according to the manufacturer's protocol. The labeled proteins were observed by enhanced chemiluminescence using detection buffer and exposure to X-ray film. The cytokines were represented as dots with different intensity and growth size.

Quantitative analysis of IL- 6 by ELISA. Supernatants of hMSC were collected. IL- 6 concentration was measured using the ELISA kit human IL-6 (Disclose SAS, Besancon Codex, France). All experiments were investigated in duplicate. The plate was read at $450 \mathrm{~nm}$ (Titertek Multiskan PLUS; Labsystems, Helsinki, Finland). IL-6 concentration $(\mathrm{pg} / \mathrm{ml})$ was ascertained by creating a standard curve using recombinant IL-6. DMEM without supplements served as the control.

Cell proliferation analysis. Cells $\left(2 \times 10^{4}\right)(\mathrm{FaDu}$ and $\mathrm{HLaC} 78)$ were incubated with hMSC-sup at $37^{\circ} \mathrm{C}$ with $5 \% \mathrm{CO}_{2}$ for 4 days, while electronically counting the cell number each day (Casy ${ }^{\circledR}$ Technologies, Innovatis AG, Reutlingen, Germany). DMEM-EM served as the control $(\mathrm{n}=5)$.

Simultaneously, the effect of IL-6 on cell proliferation was evaluated by using the MTT assay. Cells were seeded at a density of $1 \times 10^{4}$ in a 96 -well rounded bottom plate. After an incubation period of $24 \mathrm{~h}$ in DMEM-EM, hMSC-sup +/- antiIL-6 $500 \mathrm{ng} / \mathrm{ml}$ (R\&D Systems, Wiesbaden-Nordenstadt, Germany) cells were washed with PBS. Then all plates were incubated with $100 \mu \mathrm{l}$ of MTT solution $(1 \mathrm{mg} / \mathrm{ml})$ followed by $5 \mathrm{~h}$ of incubation at $37^{\circ} \mathrm{C}$ with $5 \% \mathrm{CO}_{2}$. After removal of MTT, $100 \mu \mathrm{l}$ of isopropanol was added for $1 \mathrm{~h}$ at $37^{\circ} \mathrm{C}$ with $5 \%$ $\mathrm{CO}_{2}$. The plate was read at a wavelength of $570 \mathrm{~nm}$ (Titertek Multiskan) ( $\mathrm{n}=5)$.

Total RNA extraction, cDNA synthesis and real-time PCR. The expression of EGFR in FaDu and HLaC78 were investigated as follows: According to the manufacturer's protocol, the TRIzol method was used in order to extract total RNA from cells. Next, the extracted total RNA was reverse transcribed to cDNA. For the quantification of gene expression, the SYBR Green PCR master mix kit (Applied Biosystems, Foster City, CA, USA) was used. The EGFR primer was purchased from Applied Biosystems (forward primer 5'-GCGTTCGGCACGGTGTATAA-3' and reverse primer 5'-GGCTTTCGGAGATGTTGCTTC-3'). The conditions for gene amplification were as follows: $50^{\circ} \mathrm{C}$ for $2 \mathrm{~min} ; 95^{\circ} \mathrm{C}$ for $10 \mathrm{~min}$, and 40 cycles at $95^{\circ} \mathrm{C}$ for $15 \mathrm{sec}$ and $60^{\circ} \mathrm{C}$ for $1 \mathrm{~min}$. As an endogenous control, the GAPDH gene was used. 

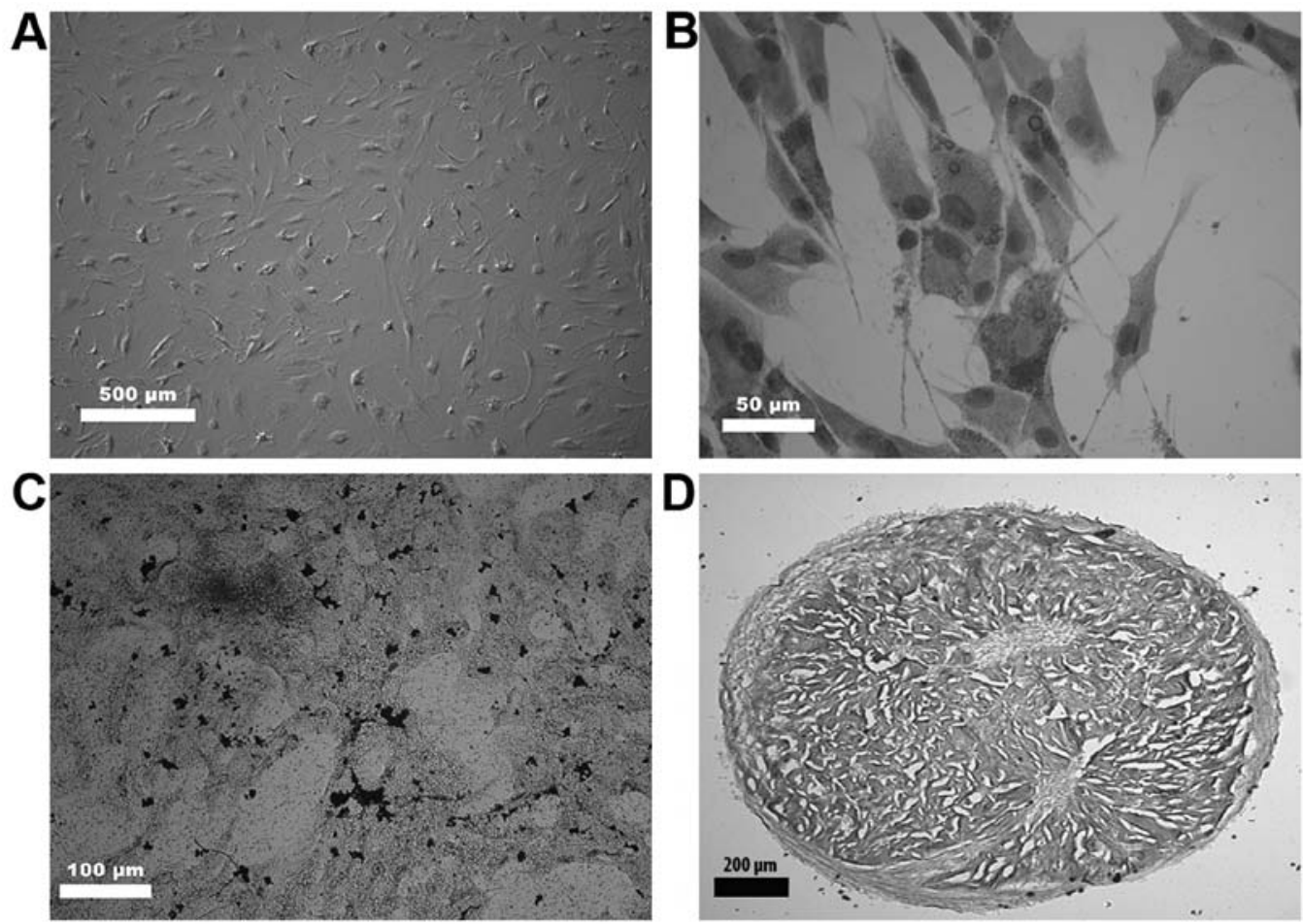

Figure 1. (A) Microscopic investigation of hMSC cultured in DMEM-EM. (B) hMSC cultivated in adipogenic medium was stained with Oil Red O. The intracellular lipid droplets are visible as a sign of adipogenic differentiation. (C) Microscopic analysis of hMSC treated with osteogenic medium for 3 weeks. The van Kossa staining shows mineralized nodule formation by hMSC. (D) Representative example of hMSC differentiated into chondrocytes. The Alcian blue staining reveals the presence of glycosaminoglycans.

Western blotting. Cells (FaDu and HLaC78) were harvested by trypsinization and dissolved in RIPA buffer (PBS, containing $1 \%$ NP40, $0.5 \%$ sodium deoxycholate and $0.1 \%$ SDS), supplemented with $10 \mu \mathrm{g} / \mathrm{ml}$ phenylmethanesulfonyl fluoride (PMSF). Protein concentration was then determined. Equal amounts of total protein lysates were loaded on a $10 \%$ SDS-polyacrylamide gel and transferred by electroblotting to a polyvinylidene difluoride membrane. Blots were blocked for $1 \mathrm{~h}$ at room temperature with TBST (10 mM Tris, $150 \mathrm{mM}$ $\mathrm{NaCl}, 0.05 \%$ Tween-20, pH 8.0), containing 5\% nonfat dry milk. Afterwards, the membrane was incubated with primary antibody ERK1/2 (Cell Signaling Technology, Beverly, MA, USA) overnight at $4^{\circ} \mathrm{C}$. Subsequently, the membrane was washed and incubated with a species-specific IgG secondary antibody for $1 \mathrm{~h}$ to visualize the specific bindings. The protein expression was detected with a chemiluminescence system (ECL, Amersham Biosciences, Freiburg, Germany), according to the manufacturer's protocol.

Statistical analysis. All data were transferred to standard spreadsheets. Differences between groups were examined for significance by the Kruskal-Wallis test using GraphPad Prism 6.0 statistics software (GraphPad Software, Inc., San Diego, CA, USA). Differences were considered statistically significant when the P-value was $<0.05$.

\section{Results}

hMSC morphology and differentiation capability. hMSC exhibited a fibroblast-shaped morphology. They were able to differentiate into chondrocytes, adipocytes and osteocytes,
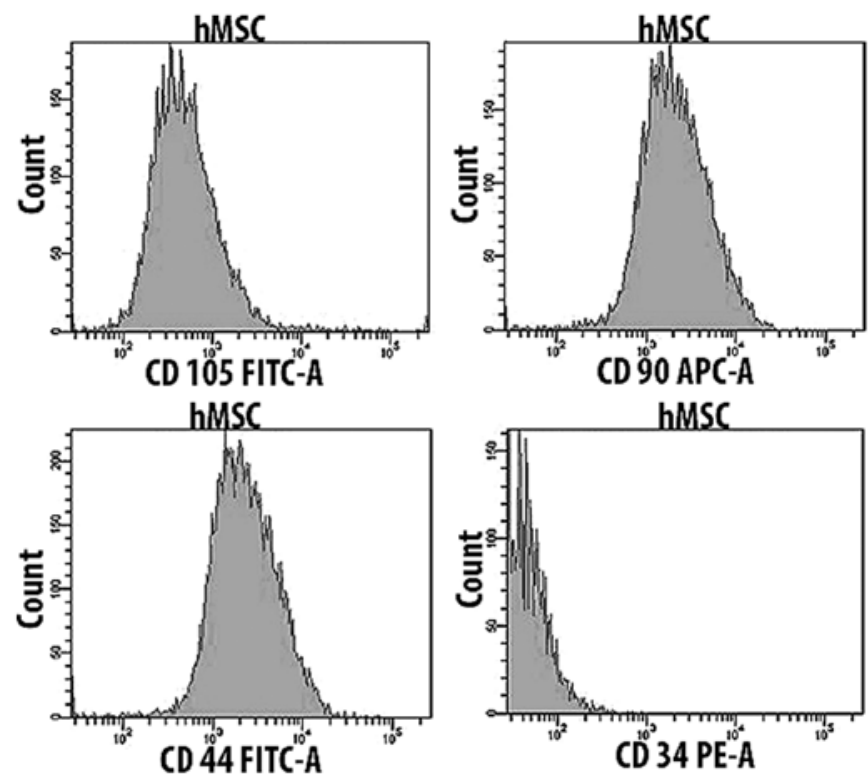

Figure 2. Flow cytometric analysis of the hMSC surface marker. The flow cytometric histograms reveal the expression of CD90, CD73 and CD44 by hMSC. It further shows the absence of CD34.

which were confirmed by Alcian blue, Oil Red $\mathrm{O}$ and van Kossa staining. The flow cytometric analysis revealed the presence of typical surface markers. hMSC were positive for CD105, CD90 and CD44, and negative for CD34 (Figs. 1 and 2).

HNSCC cell line morphology before and after cultivation with hMSC-sup. Morphology of FaDu and HLaC78 was 
Table I. Cytokines map.

\begin{tabular}{llllllllllll}
\hline+ & + & - & - & ENA-78 & GCSF & GM-CSF & GRO & GRO- $\alpha$ & I-309 & IL-1 $\alpha$ & IL-1 $\beta$ \\
+ & + & - & - & ENA-78 & GCSF & GM-CSF & GRO & GRO- $\alpha$ & I-309 & IL-1 $\alpha$ & IL-1 $\beta$ \\
IL-2 & IL-3 & IL-4 & IL-5 & IL-6 & IL-7 & IL-8 & IL-10 & IL-12 & IL-13 & IL-15 & IFN- $\gamma$ \\
IL-2 & IL-3 & IL-4 & IL-5 & IL-6 & IL-7 & IL-8 & IL-10 & IL-12 & IL-13 & IL-15 & IFN- $\gamma$ \\
MCP-1 & MCP-2 & MCP-3 & MCSF & MCD & MIG & MIP-1d & RANTES & SCF & SDF-1TA & RC & TGF- $\beta 1$ \\
MCP-1 & MCP-2 & MCP-3 & MCSF & MCD & MIG & MIP-1d & RANTES & SCF & SDF-1TA & RC & TGF- $\beta 1$ \\
TNF- $\alpha$ & TNF- $\beta$ & EGF & IGF-1 & Angiogenin & OncostatinM & Thrombopoietin & VEGF & PDGF-BB & Leptin & - & + \\
TNF- $\alpha$ & TNF- $\beta$ & EGF & IGF-1 & Angiogenin & OncostatinM & Thrombopoietin & VEGF & PDGF-BB & Leptin & - & + \\
\hline
\end{tabular}

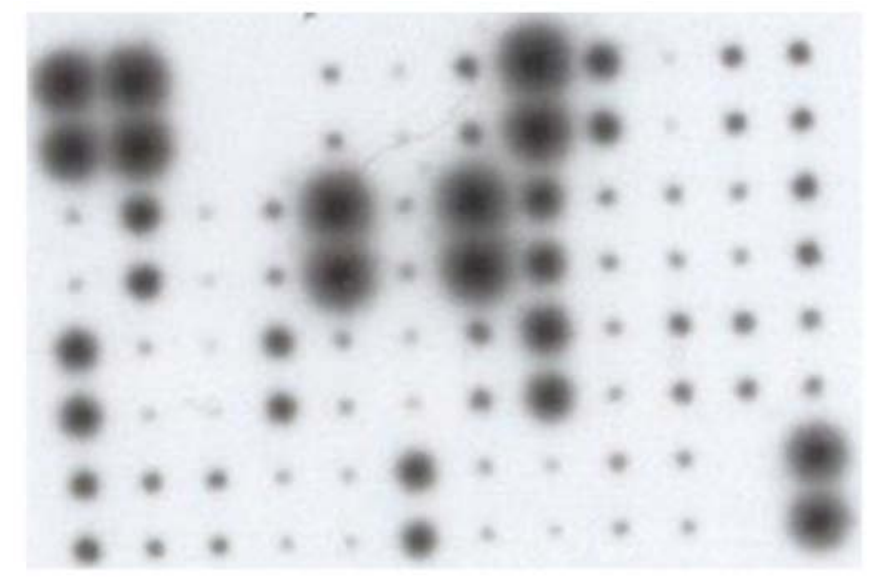

Figure 3. Cytokine assay of hMSC cultivated with DMEM without supplements. After $24 \mathrm{~h}$ the cytokines were measured using the dot blot assay. hMSC released various types of cytokines which are responsible for angiogenesis, inflammation and growth. To unscramble the different dots, a table included in the manufacturer's protocol was used (see Table I).

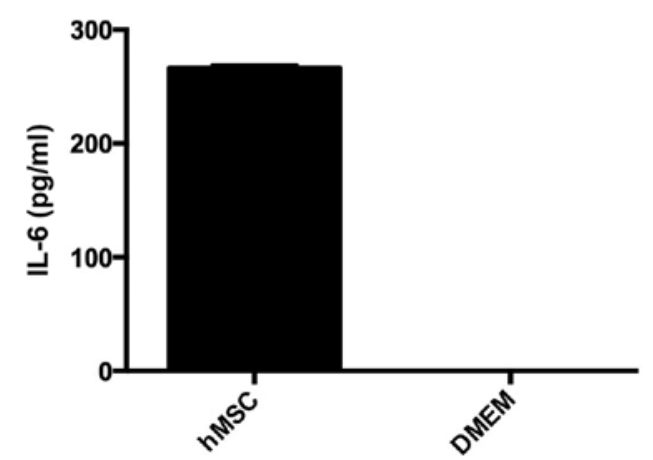

Figure 4. Supernatants of hMSC were collected and investigated for the presence of IL-6. The ELISA method was used. hMSC in monolayer culture released $260 \mathrm{pg} / \mathrm{ml}$ IL-6. DMEM without supplements served as the control. IL-6 in DMEM was not detected.

evaluated before and after cultivation with hMSC-sup for $48 \mathrm{~h}$. Microscopy revealed no differences in cell morphology between each group for both cell lines.

Cytokine secretion by hMSC. The dot blot assay was used to evaluate different cytokines in the hMSC supernatants. hMSC supernatants contained a variety of cytokines responsible for pro- and anti-inflammation, chemotaxis, angiogenesis and
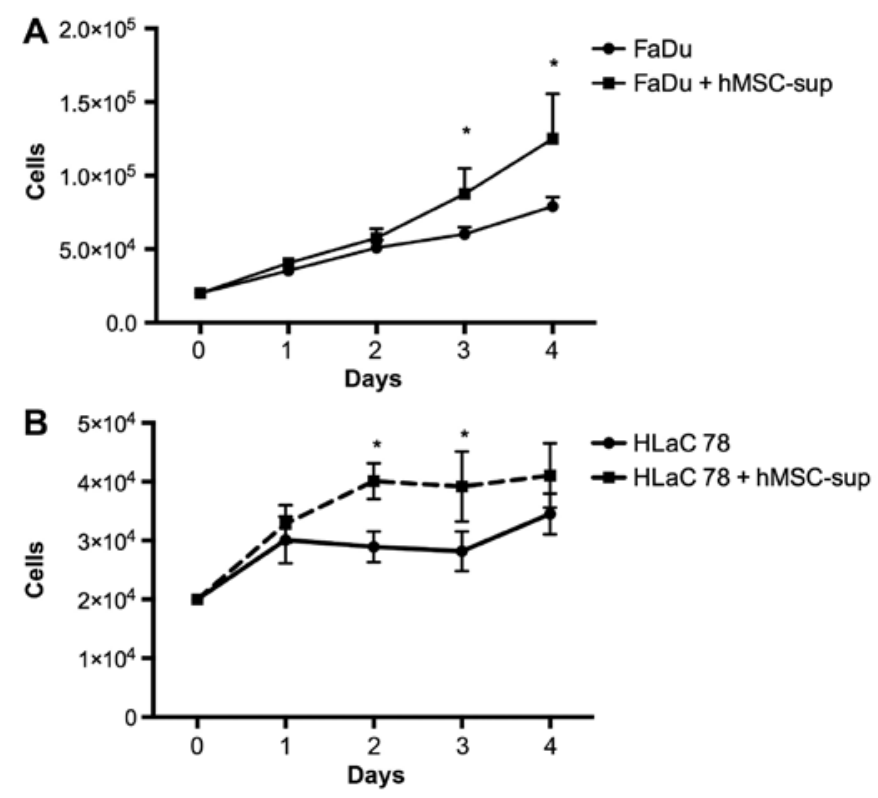

Figure 5. The effect of hMSC on cell proliferation was analyzed by cell counting. In a 24-well plate HNSCC cell lines FaDu and HLaC78 were cultured with hMSC-sup. Each day the cell number was counted. FaDu and HLaC78 cultured in DMEM-EM served as the control.

growth factors. The dots of the following cytokines had a strong intensity: interleukin (IL)-3; IL-6, IL-8, IL-10, Growth regulated oncogene (GRO), GRO- $\alpha$, Monocyte chemotactic protein (MCP)-1, Macrophage colony-stimulating factor, Stem cell factor, Tumor necrosis factor (TNF)- $\alpha$ and OncostatinM (Fig. 3 and Table I).

Quantitative analysis of IL-6. The secretion of IL-6 was quantified with the ELISA method. hMSC in monolayer culture released $260 \mathrm{pg} / \mathrm{ml}$ IL-6. DMEM without supplements as control did not contain IL-6 (Fig. 4).

Effects of hMSC on HNSCC proliferation +/- anti-IL-6. The cultivation of $\mathrm{FaDu}$ and $\mathrm{HLaC78}$ with hMSC-sup induced a significant enhancement of cell proliferation compared to cultivation in DMEM-EM. The MTT assay confirmed the results of the cell counting. FaDu and HLaC78 showed a significant enhancement of cell proliferation. The impact of IL- 6 on cell proliferation was investigated by the addition of anti-IL-6 into hMSC-sup. Anti-IL-6 induced the inhibition of cell proliferation. FaDu and HLaC78 showed a reduction 

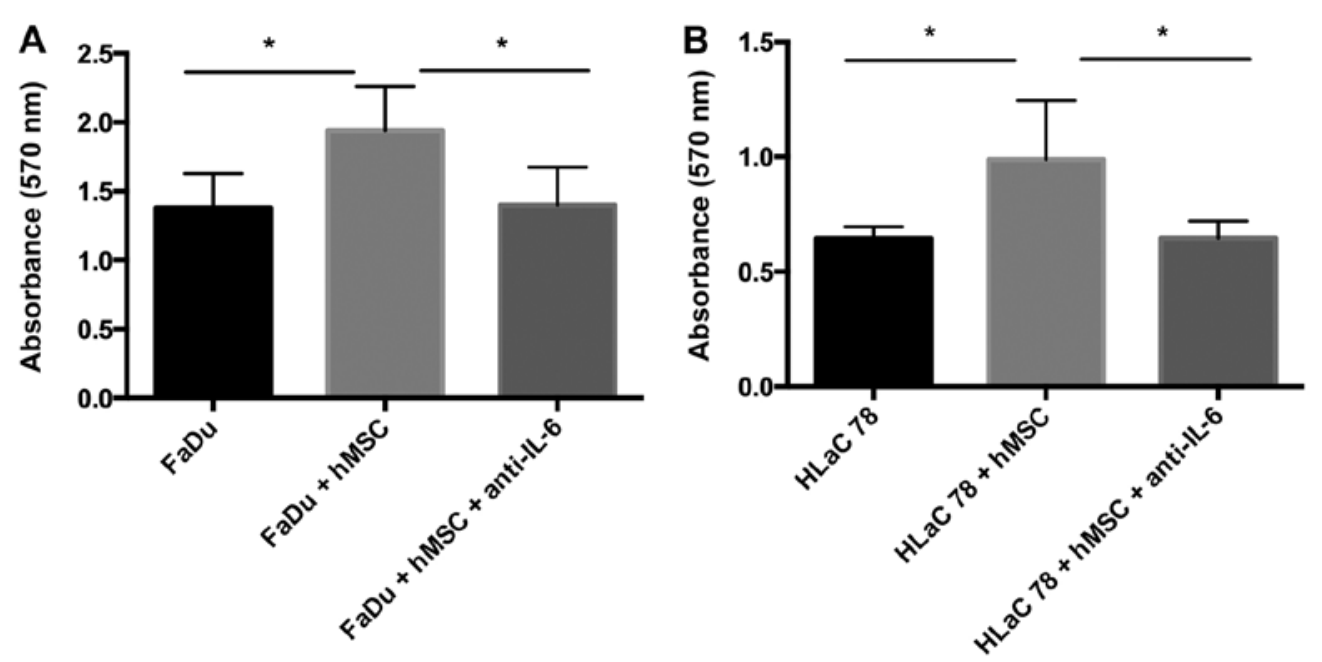

Figure 6. The IL-6-dependent increase in cell proliferation was examined by cell cultivation of FaDu and HLaC78 with hMSC-sup +/- anti-IL-6. The MTT assay was used to investigate the influence of IL- 6 on cell proliferation. After the addition of anti-IL- 6 the proliferation enhancement was blocked.

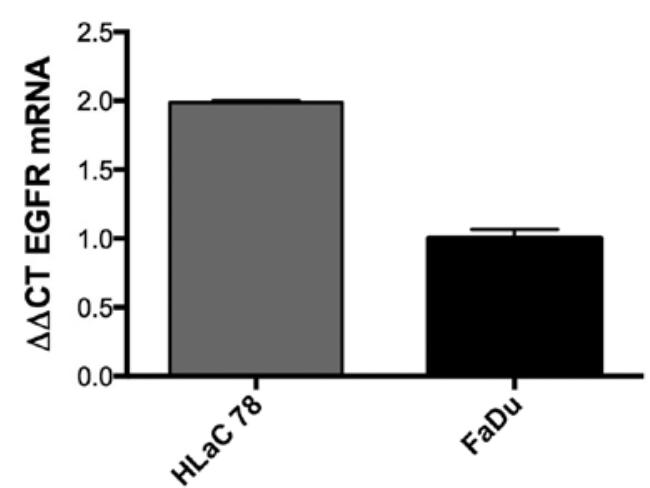

Figure 7. The EGF receptor expression on FaDu and HLaC78 was investigated using rt-PCR. Values are expressed using the $\Delta \Delta \mathrm{Ct}$ method. HLaC78 were shown to express almost 2-fold more EGFR than FaDu.

in cell proliferation compared to cultivation with hMSC-sup without anti-IL-6 (Figs. 5 and 6).

Expression of EGFR in HNSCC. GFR gene expression was assessed by real-time PCR in FaDu and HLaC78. Values were expressed using the $\Delta \Delta \mathrm{Ct}$ method to derive relative fold change. Both cell lines were positive for EGFR expression. The EGFR expression was almost 2-fold more in HLaC78 compared to FaDu (Fig. 7).

Activation of ERK1/2. The expression of ERK1/2 and the corresponding phosphorylated protein in FaDu and HLaC78 was investigated with the western blotting. Western blot analysis revealed expression of ERK1/2 as well as its phosphorylated protein after cultivation in hMSC-sup. The cultivation in DMEM-EM revealed total absence of the phosphorylated protein (Fig. 8).

\section{Discussion}

Solid tumors are embedded into a complex microenvironment, which includes several types of non-malignant cells, malignant cells as well as extracellular matrix. On one hand, cytokines

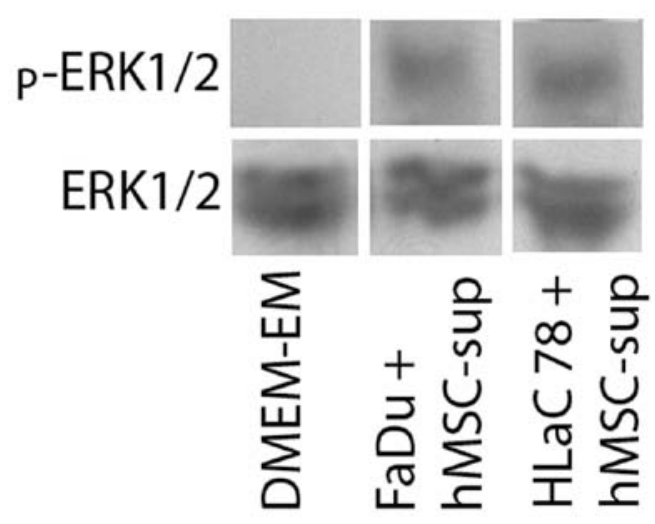

Figure 8. The expression levels of ERK1/2 and the phosphorylated ERK1/2 (P-ERK1/2) were examined by western blot analysis in FaDu and HLaC78 treated with hMSC-sup. The western blotting showed the expression of ERK1/2 in FaDU and HLaC78 after cultivation in DMEM-EM as well as in hMSC-sup. P-ERK1/2 was present only in cells cultivated with hMSC-sup.

produced by tumor cells alter the gene expression of stromal cells and their phenotypical properties. On the other hand, the cancer cells release growth factors, cytokines and proteases which enhance tumor growth $(26,27)$. Cancer and stroma interact in an autocrine as well as paracrine manner. This implies the symbiotic relationship between cancer and cancer surrounding stroma. Several cytokines responsible for inflammation and angiogenesis are elevated in the serum of patients with HNSCC compared to the control group (28). IL-6, a multifunctional regulator of immune responses and hematopoiesis, influences the proliferation and invasion potential of head and neck cancer directly (29). IL-6 regulates a complex network of cytokines responsible for inflammation, growth factors as well as angiogenic proteins which lead to malignant and invasive tumor growth (30). In the current study, the cultivation of the HNSCC cell lines FaDu and HLaC78 with hMSC-sup resulted in proliferation enhancement of tumor cells. The dot blot of hMSC-sup revealed the secretion of various cytokines and growth factors by hMSC. The dots of several cytokines, especially IL-6, had a strong intensity. 
The addition of anti-IL- 6 counteracted these pro-mitotic effects of hMSC-sup. In the current study, a significant attenuation of HNSCC cell proliferation in the culture system treated with anti-IL-6 compared to cells treated with hMSCsup was detected. This is an indirect marker for the impact of IL- 6 on cancer progression. Furthermore, IL-6 can be responsible for the development of resistance towards anticancer drugs such as cisplatin (31). This was achieved by an increased expression of the cellular inhibitor of apoptosis 2 (cIAP-2) via IL-6. The effect was reversible by the addition of anti-IL-6 and anti-cIAP-2.

In the current study, the proliferation enhancement of $\mathrm{FaDu}$ and HLaC78 was induced via activation of ERK1/2. The Erk1/2 pathway is a critical signal transduction pathway in the mitogen-activated protein kinase family, and is closely associated with tumorigenesis and tumor progression (32). Erk1/2 targets different molecules that are responsible for cell growth, survival, adhesion, motility and differentiation $(32,33)$. The activation of ERK1/2 via hMSC seems to be crucial for cell proliferation. IL-6 was shown by Shi et al to stimulate tumor growth by activation of Ras, Raf, MEK, and Erk1 and 2 (34). IL-6 induces different intracellular signaling cascades, e.g. JAK-STAT, MAPK and PI3K $(35,36)$.

In malignant mammary carcinoma the activation of Erk1/2 has been associated with a poor prognosis (20). Due to their ability to be recruited by damaged tissues, inflammation and cancer, hMSC have been discussed as being a very promising vehicle for cancer treatment. However, many studies in this area do not consider the interactions between stem cells and cancer. There are studies showing a tumorigenic effect of hMSC $(13,15,18)$, as well as reports on cancer inhibition by hMSC $(37,38)$.

Karnoub et al were able to show that hMSC enhanced the metastatic potential of breast carcinoma cells by de novo secretion of RANTES, which represents a potent cytokine responsible for cancer cell motility, invasion and migration (13). The dot blot assay revealed the secretion of RANTES by hMSC. In a previous study by our group, the enhancement of cancer cell motility was demonstrated (22). Co-injection of hMSC and breast cancer cells resulted in cancer progression (15).

One important issue in cancer progression is the ability of hMSC to integrate into tumor stroma and differentiate into cancer-associated fibroblasts (CAF) $(10,39,40)$. Longterm co-culture of hMSC with cancer supernatants resulted in a differentiation of hMSC into myofibroblasts (41). These CAF (differentiated hMSC) are able to release cytokines responsible for cancer growth and matrix remodeling (42). Furthermore, CAF are able to express proteins involved in lactate absorption, lactate oxidation and reduced glucose absorption (43). CAF sustain cancer cell survival by buffering and recycling products of anaerobic metabolism (43). Cancer-associated fibroblasts are involved in the initiation of cancer invasion (44).

In contrast to studies showing the tumor-supporting potential of hMSC, there are also studies indicating anticancer effects: As shown by Khakoo, the inhibition of Kaposi sarcoma was induced via suppression of Akt protein kinase by hMSC.
Qiao et al demonstrated inhibition of human hepatoma cell lines via the Wnt signaling pathway (37). Zhu et al presented the DKK-1 (dickkopf-1) protein as a negative regulator of the Wnt signaling pathway (38). In a study conducted by Qiao et al hMSC inhibited cancer cell growth by secretion of DKK-1 (45). The reason for these contradictory findings may be explained by the use of different stem cell sources as well as different donor ages. Thus, the use of stem cells as a carrier for cancer therapy must be critically discussed. A possible solution may be the use of genetically engineered stem cells with, for example, the absence of IL-6 secretion. Therefore, a challenging future mission will be to identify an optimal stem cell with enhanced tumor tropism and highly anti-tumorigenic potential.

\section{References}

1. Pittenger MF, Mackay AM, Beck SC, Jaiswal RK, Douglas R, Mosca JD, Moorman MA, Simonetti DW, Craig S and Marshak DR: Multilineage potential of adult human mesenchymal stem cells. Science 284: 143-147, 1999.

2. Bianco P, Riminucci M, Gronthos S and Robey PG: Bone marrow stromal stem cells: Nature, biology, and potential applications. Stem Cells 19: 180-192, 2001.

3. Coffelt SB, Marini FC, Watson K, Zwezdaryk KJ, Dembinski JL, LaMarca HL, Tomchuck SL, Honer zu Bentrup K, Danka ES, Henkle SL, et al: The pro-inflammatory peptide LL-37 promotes ovarian tumor progression through recruitment of multipotent mesenchymal stromal cells. Proc Natl Acad Sci USA 106: 3806-3811, 2009.

4. Asahara T, Masuda H, Takahashi T, Kalka C, Pastore C, Silver M, Kearne M, Magner M and Isner JM: Bone marrow origin of endothelial progenitor cells responsible for postnatal vasculogenesis in physiological and pathological neovascularization. Circ Res 85: 221-228, 1999.

5. Malek S, Kaplan E, Wang JF, Ke Q, Rana JS, Chen Y, Rahim BG, Li M, Huang Q, Xiao YF, et al: Successful implantation of intravenously administered stem cells correlates with severity of inflammation in murine myocarditis. Pflugers Arch 452: 268-275, 2006.

6. Campbell JJ and Butcher EC: Chemokines in tissue-specific and microenvironment-specific lymphocyte homing. Curr Opin Immunol 12: 336-341, 2000.

7. Von Lüttichau I, Notohamiprodjo M, Wechselberger A, Peters C, Henger A, Seliger C, Djafarzadeh R, Huss R and Nelson PJ: Human adult CD34 progenitor cells functionally express the chemokine receptors CCR1, CCR4, CCR7, CXCR5, and CCR10 but not CXCR4. Stem Cells Dev 14: 329-336, 2005.

8. Dvorak HF: Tumors: Wounds that do not heal. Similarities between tumor stroma generation and wound healing. N Engl J Med 315: 1650-1659, 1986.

9. Kidd S, Caldwell L, Dietrich M, Samudio I, Spaeth EL, Watson K, Shi Y, Abbruzzese J, Konopleva M, Andreeff M, et al: Mesenchymal stromal cells alone or expressing interferon-beta suppress pancreatic tumors in vivo, an effect countered by antiinflammatory treatment. Cytotherapy 12: 615-625, 2010.

10. Spaeth EL, Dembinski JL, Sasser AK, Watson K, Klopp A, Hall B, Andreeff M and Marini F: Mesenchymal stem cell transition to tumor-associated fibroblasts contributes to fibrovascular network expansion and tumor progression. PLoS One 4: e4992, 2009.

11. Huang Q, Liu XZ, Kang CS, Wang GX, Zhong Y and Pu PY: The anti-glioma effect of suicide gene therapy using BMSC expressing HSV/TK combined with overexpression of $\mathrm{Cx} 43$ in glioma cells. Cancer Gene Ther 17: 192-202, 2010.

12. Cavarretta IT, Altanerova V, Matuskova M, Kucerova L, Culig Z and Altaner C: Adipose tissue-derived mesenchymal stem cells expressing prodrug-converting enzyme inhibit human prostate tumor growth. Mol Ther 18: 223-231, 2010.

13. Karnoub AE, Dash AB, Vo AP, Sullivan A, Brooks MW, Bell GW, Richardson AL, Polyak K, Tubo R and Weinberg RA: Mesenchymal stem cells within tumour stroma promote breast cancer metastasis. Nature 449: 557-563, 2007. 
14. Lin WR, Brittan M and Alison MR: The role of bone marrowderived cells in fibrosis. Cells Tissues Organs 188: 178-188, 2008.

15. Rhodes LV, Muir SE, Elliott S, Guillot LM, Antoon JW, Penfornis P, Tilghman SL, Salvo VA, Fonseca JP, Lacey MR, et al: Adult human mesenchymal stem cells enhance breast tumorigenesis and promote hormone independence. Breast Cancer Res Treat 121: 293-300, 2010.

16. Kemp KC, Hows J and Donaldson C: Bone marrow-derived mesenchymal stem cells. Leuk Lymphoma 46: 1531-1544, 2005.

17. Wang Y, Wang M, Abarbanell AM, Weil BR, Herrmann JL, Tan J, Novotny NM, Coffey AC and Meldrum DR: MEK mediates the novel cross talk between TNFR 2 and TGF-EGFR in enhancing vascular endothelial growth factor (VEGF) secretion from human mesenchymal stem cells. Surgery 146: 198-205, 2009.

18. Scherzed A, Hackenberg S, Froelich K, Kessler M, Koehler C, Hagen R, Radeloff A, Friehs G and Kleinsasser N: BMSC enhance the survival of paclitaxel treated squamous cell carcinoma cells in vitro. Cancer Biol Ther 11: 349-357, 2011.

19. Park JI: Growth arrest signaling of the Raf/MEK/ERK pathway in cancer. Front Biol (Beijing) 9: 95-103, 2014.

20. Whyte J, Bergin O, Bianchi A, McNally S and Martin F: Key signalling nodes in mammary gland development and cancer Mitogen-activated protein kinase signalling in experimental models of breast cancer progression and in mammary gland development. Breast Cancer Res 11: 209, 2009.

21. Dhillon AS, Hagan S, Rath O and Kolch W: MAP kinase signalling pathways in cancer. Oncogene 26: 3279-3290, 2007.

22. Scherzed A, Hackenberg S, Radeloff A, Froelich K, Rak K, Hagen R and Kleinsasser N: Human mesenchymal stem cells promote cancer motility and cytokine secretion in vitro. Cells Tissues Organs 198: 327-337, 2013.

23. Lee RH, Kim B, Choi I, Kim H, Choi HS, Suh K, Bae YC and Jung JS: Characterization and expression analysis of mesenchymal stem cells from human bone marrow and adipose tissue. Cell Physiol Biochem 14: 311-324, 2004.

24. Rangan SR: A new human cell line $(\mathrm{FaDu})$ from a hypopharyngeal carcinoma. Cancer 29: 117-121, 1972.

25. Zenner HP, Lehner W and Herrmann IF: Establishment of carcinoma cell lines from larynx and submandibular gland. Arch Otorhinolaryngol 225: 269-277, 1979.

26. Witz IP: Tumor-microenvironment interactions: Dangerous liaisons. Adv Cancer Res 100: 203-229, 2008.

27. Zigrino P, Löffek S and Mauch C: Tumor-stroma interactions: Their role in the control of tumor cell invasion. Biochimie 87 321-328, 2005.

28. Chen Z, Malhotra PS, Thomas GR, Ondrey FG, Duffey DC, Smith CW, Enamorado I, Yeh NT, Kroog GS, Rudy S, et al: Expression of proinflammatory and proangiogenic cytokines in patients with head and neck cancer. Clin Cancer Res 5: $1369-1379,1999$.

29. Kanazawa T, Nishino H, Hasegawa M, Ohta Y, Iino Y, Ichimura K and Noda Y: Interleukin-6 directly influences proliferation and invasion potential of head and neck cancer cells. Eur Arch Otorhinolaryngol 264: 815-821, 2007.

30. Lederle W, Depner S, Schnur S, Obermueller E, Catone N, Just A, Fusenig NE and Mueller MM: IL-6 promotes malignant growth of skin SCCs by regulating a network of autocrine and paracrine cytokines. Int J Cancer 128: 2803-2814, 2011.
31. Cohen S, Bruchim I, Graiver D, Evron Z, Oron-Karni V, Pasmanik-Chor M, Eitan R, Bernheim J, Levavi H, Fishman A, et al: Platinum-resistance in ovarian cancer cells is mediated by IL-6 secretion via the increased expression of its target cIAP-2. J Mol Med Berl 91: 357-368, 2013.

32. Chang H, Shi Y, Tuokan T, Chen R and Wang X: Expression of aquaporin 8 and phosphorylation of Erk1/2 in cervical epithelial carcinogenesis: Correlation with clinicopathological parameters. Int J Clin Exp Pathol 7: 3928-3937, 2014.

33. Hsu YL, Hou MF, Kuo PL, Huang YF and Tsai EM: Breast tumor-associated osteoblast-derived CXCL5 increases cancer progression by ERK/MSK1/Elk-1/snail signaling pathway. Oncogene 32: 4436-4447, 2013.

34. Shi Y, Hsu JH, Hu L, Gera J and Lichtenstein A: Signal pathways involved in activation of p70S6K and phosphorylation of 4E-BP1 following exposure of multiple myeloma tumor cells to interleukin-6. J Biol Chem 277: 15712-15720, 2002.

35. Levy DE and Darnell JE Jr: Stats: Transcriptional control and biological impact. Nat Rev Mol Cell Biol 3: 651-662, 2002.

36. Rose-John S, Scheller J, Elson G and Jones SA: Interleukin-6 biology is coordinated by membrane-bound and soluble receptors: Role in inflammation and cancer. J Leukoc Biol 80: 227-236, 2006.

37. Qiao L, Xu Z, Zhao T, Zhao Z, Shi M, Zhao RC, Ye L and Zhang X: Suppression of tumorigenesis by human mesenchymal stem cells in a hepatoma model. Cell Res 18: 500-507, 2008.

38. Zhu Y, Sun Z, Han Q, Liao L, Wang J, Bian C, Li J, Yan X, Liu Y, Shao C, et al: Human mesenchymal stem cells inhibit cancer cell proliferation by secreting DKK-1. Leukemia 23: 925-933, 2009.

39. Liu R, Wei S, Chen J and Xu S: Mesenchymal stem cells in lung cancer tumor microenvironment: Their biological properties, influence on tumor growth and therapeutic implications. Cancer Lett 353: 145-152, 2014.

40. Direkze NC, Hodivala-Dilke K, Jeffery R, Hunt T, Poulsom R, Oukrif D, Alison MR and Wright NA: Bone marrow contribution to tumor-associated myofibroblasts and fibroblasts. Cancer Res 64: 8492-8495, 2004.

41. Mishra PJ, Mishra PJ, Humeniuk R, Medina DJ, Alexe G, Mesirov JP, Ganesan S, Glod JW and Banerjee D: Carcinomaassociated fibroblast-like differentiation of human mesenchymal stem cells. Cancer Res 68: 4331-4339, 2008.

42. Silzle T, Kreutz M, Dobler MA, Brockhoff G, Knuechel R and Kunz-Schughart LA: Tumor-associated fibroblasts recruit blood monocytes into tumor tissue. Eur J Immunol 33: 13111320, 2003.

43. Koukourakis MI, Giatromanolaki A, Harris AL and Sivridis E: Comparison of metabolic pathways between cancer cells and stromal cells in colorectal carcinomas: A metabolic survival role for tumor-associated stroma. Cancer Res 66: 632-637, 2006.

44. De Wever O and Mareel M: Role of tissue stroma in cancer cell invasion. J Pathol 200: 429-447, 2003.

45. Qiao L, Xu ZL, Zhao TJ, Ye LH and Zhang XD: Dkk-1 secreted by mesenchymal stem cells inhibits growth of breast cancer cells via depression of Wnt signalling. Cancer Lett 269: 67-77, 2008. 